\title{
Blunt-ended telomeres: an alternative ending to the replication and end protection stories
}

\author{
Andrew D.L. Nelson and Dorothy E. Shippen ${ }^{1}$ \\ Department of Biochemistry and Biophysics, Texas A\&M University, College Station, Texas 77843, USA
}

Telomeres ensure the complete replication of genetic material while simultaneously distinguishing the chromosome terminus from a double-strand break. A prevailing theme in telomere biology is that the two chromosome ends are symmetrical. Both terminate in a single-strand 3' extension, and the $3^{\prime}$ extension is crucial for telomere end protection. In this issue of Genes \& Development, Kazda and colleagues (pp. 1703-1713) challenge this paradigm using a series of elegant biochemical and genetic assays to demonstrate that half of the chromosomes in flowering plants are blunt-ended. This discovery reveals unanticipated complexity in telomeric DNA processing and a novel mode of chromosome end protection.

The architecture of telomeres is highly conserved across eukarya. Telomeres typically consist of long tracts of a G-rich repeat (TTAGGG and TTTAGGG in vertebrates and plants, respectively), terminating in a $3^{\prime}$ single-strand extension known as the G-overhang (Henderson and Blackburn 1989; Wellinger et al. 1993). The telomere repeat array is synthesized and maintained by telomerase, but even in flies, which lack telomerase and instead maintain retrotransposons on their chromosome ends, there is the potential for single-strand overhangs (Raffa et al. 2010). G-overhangs are the operation center for critical telomere activities: They prime telomere repeat incorporation by telomerase and instigate the assembly of higher-order structures to protect the terminus against illicit DNA repair activities. Not surprisingly, molecular exchanges involving the G-overhang are highly orchestrated and are facilitated by a large suite of DNA replication and processing enzymes as well as telomere-associated proteins.

The G-overhang is a by-product of both the semiconservative nature of chromosomal DNA replication and tightly controlled exonucleolytic processing (Fig. 1). DNA replication via the leading strand mechanism produces

[Keywords: telomere; telomerase; t-circle; Arabidopsis; recombination; Ku] ${ }^{1}$ Corresponding author

E-mail dshippen@tamu.edu

Article is online at http://www.genesdev.org/cgi/doi/10.1101/gad.199059.112. a full-length daughter strand. In contrast, lagging strand synthesis does not generate a complete copy of the DNA. When the last RNA primer is removed from the extreme 5 ' end of the daughter strand, an unreplicated gap is created, resulting in a $3^{\prime}$ G-overhang. With successive rounds of DNA replication, the aptly named "end replication problem" ensues, resulting in loss of terminal sequences (Watson 1972; Olovnikov 1973). Whereas imprecise placement of the RNA primer would result in heterogeneous G-overhang length for the lagging end telomere, and leading strand synthesis would result in no overhang for the leading end, neither of these final end products is observed. Rather, sequence analysis reveals very precise 5 ' processing of the C-rich telomeric strand (Sfeir et al. 2005), arguing that a highly controlled C-strand resectioning event follows DNA replication (Makarov et al. 1997).

The two main chromosome end-binding complexes shelterin and CTC1/STN1/TEN1 (CST) are obvious candidates to regulate $\mathrm{C}$-strand resection. These complexes are required to complete replication of the chromosome end and block telomere fusion events, and both possess integral constituents that bind the G-overhang (de Lange 2005; Price et al. 2010). Intriguingly, however, it is the proteins that contact the telomeric duplex that control C-strand resection. In vertebrates, the shelterin component TRF2 is proposed to recruit the $5^{\prime}-3^{\prime}$ exonuclease Apollo immediately after replication of leading end telomeres (Fig. 1; van Overbeek and de Lange 2006). Removal of Apollo, or disruption of its interaction with TRF2, results in a $30 \%-40 \%$ decrease in the G-overhang signal in mice (Wu et al. 2010). In budding yeast, the double-strand telomere-binding protein Rap1, along with two accessory proteins (Rif1 and Rif2), modulates C-strand processing (Bonetti et al. 2010a). Thus, the generation of $3^{\prime}$ overhangs on leading end telomeres in yeast and vertebrates is integral to the mechanism of chromosome replication and gives rise to symmetrical chromosome ends. Chinks in this model appeared when 5' overhangs of the C-rich strand were discovered on nematode telomeres (Raices et al. 2008) and mammalian telomeres maintained by recombination (Oganesian and Karlseder 2011). Now, Riha and coworkers (Kazda et al. 


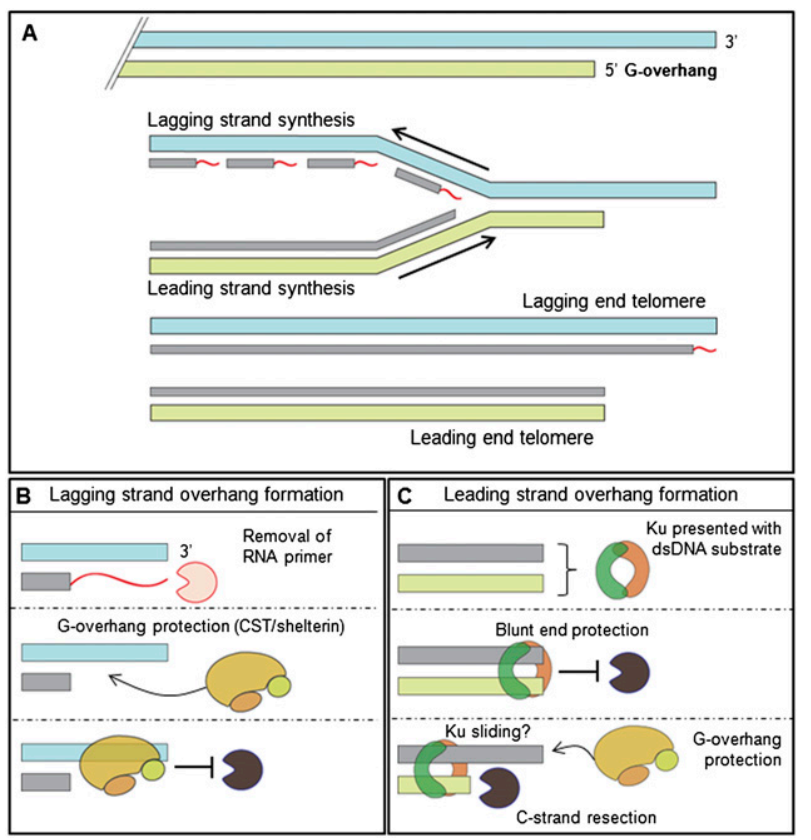

Figure 1. Replication and processing of leading and lagging end telomeres. (A) As the replication fork moves during lagging strand synthesis, multiple RNA primers (red curvy lines) are laid down to copy the DNA in short segments, termed Okazaki fragments. RNA primers are removed from the body of the chromosome, and the gaps are filled in by repair polymerases. When the last RNA primer is removed from the $5^{\prime}$ end of the daughter strand, the gap cannot be filled in. Replication of the daughter strand by leading strand machinery is continuous and creates a blunt-ended telomere. $(B)$ Degradation of the terminal RNA primer by an unknown nuclease results in the formation of a 3' G-overhang that is sequestered by CST or shelterin into a nuclease-resistant conformation. $(C)$ The blunt-ended telomere arising from leading strand synthesis is an ideal substrate for $\mathrm{Ku}$. $\mathrm{Ku}$ association would prevent nuclease attack. To allow regulated C-strand resection and the subsequent binding of $\mathrm{G}$-overhang-associated proteins, $\mathrm{Ku}$ may slide inward along the telomere.

2012) upset the symmetry by showing that, in flowering plants, leading end telomeres are not processed to create Goverhangs. Instead, half of the chromosome termini are stably maintained as blunt ends.

\section{To be blunt, plants harbor telomeres without} a 3 ' overhang

The first hint that plant telomeres might be architecturally distinct from yeast and vertebrate telomeres came more than a decade ago. Primer extension nick translation (PENT) assays carried out with Arabidopsis thaliana indicated that G-overhangs were relatively short (20-30 nucleotides [nt]). Even more curiously, only about half of the $3^{\prime}$ extensions were long enough for hybridization with a DNA primer, indicating that the remaining telomeres harbored overhangs that were extremely short $\mid<12 \mathrm{nt}$ in length) (Riha et al. 2000). These results sparked the heretical hypothesis that half of the telomeres in Arabidopsis are blunt-ended. Testing of this hypothesis required the development of novel biochemical assays involving primer extension and end ligation as well as the identification of the G-overhang-binding complex from plants: CST (Song et al. 2008; Surovtseva et al. 2009). In this issue of Genes \& Development, Kazda et al. (2012) demonstrate that Arabidopsis telomeres are indeed highly asymmetrical. The investigators first made an ingenious modification to the PENT assay by including dUTP during synthesis of the telomeric C strand. Treatment of the PENT products with uracil DNA glycosylase converts uracils into abasic sites that fragment when separated on an agarose gel under alkaline conditions. Telomeres with Goverhangs are degraded in this assay, while blunt-ended telomeres are not. The investigators confirmed that roughly half of all Arabidopsis telomeres are refractory to dUTP-PENT. The investigators went a step further by designing a series of hairpin adaptors that can be ligated to blunt-ended or nearly blunt-ended telomeres. Following hairpin ligation, blunt-ended telomeres will effectively double in size, making it possible to distinguish them from molecules bearing single-strand extensions. Kazda et al. (2012) determined that $\sim 11 \%$ of the telomeres were perfectly blunt, while a significant portion $(\sim 30 \%)$ carried a 1 - to 3 -nt $3^{\prime}$ overhang. These residual $3^{\prime}$ extensions may reflect a window of vulnerability to nucleolytic attack before the blunt-end terminus can recruit its protective cap (see below).

Recent data from human cells indicate that the primer for lagging strand replication is not synthesized at the extreme telomere terminus, but rather is situated $\sim 100$ nt from the end (Chow et al. 2012). When the RNA primer is removed, a fully mature G-overhang is generated, precluding the requirement for exonucleolytic processing on the lagging end telomere. Because G-overhangs in Arabidopsis correspond to the size of an RNA primer, the terminal RNA primer is probably laid down at the most distal position on the parental strand. Primer removal following lagging strand replication would thus create a fully mature G-overhang, obviating the need for C-strand resection. Moreover, because leading end telomeres are blunt-ended when they are mature, the activity of an enzyme like Apollo would be unnecessary in Arabidopsis. Notably, an ortholog for Apollo cannot be discerned in higher plants.

Blunt-ended telomeres could potentially represent "dead ends," processing intermediates that accumulate in postreplicative cells. Arabidopsis maintains a small cache of stem cells necessary for plant development, and these proliferating cells comprise only a tiny fraction of the biomass (Aichinger et al. 2012). Kazda et al. (2012) found the same percentage of blunt-ended telomeres in whole plants as in flowers and cell culture, sources of rapidly dividing cells. Thus, blunt-ended telomeres are a stable feature of Arabidopsis chromosomes (Fig. 2A). As expected, blunt ends were not detected on yeast or human chromosomes and were not associated with telomeres in the moss Physcomitrella patens, which lies at the base of the plant lineage. However, blunt-ended telomeres were observed in a variety of angiosperms, indicating that they are a conserved feature of land plants. 


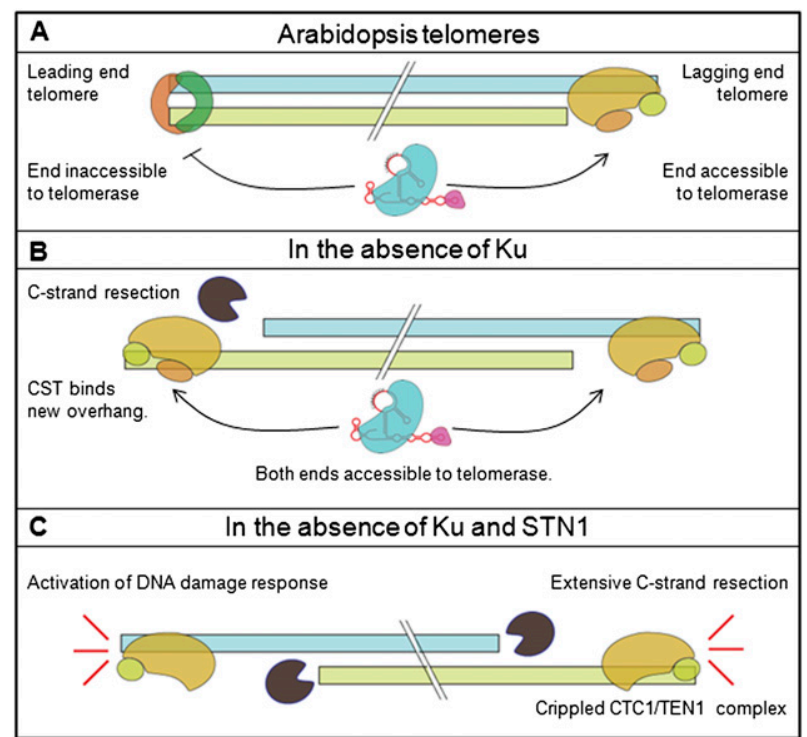

Figure 2. A model for Arabidopsis telomeres. $(A)$ Kazda et al. (2012) show that half of the telomeres are blunt-ended in Arabidopsis. Leading strand replication would create such telomeres. The blunt-end is stably bound by $\mathrm{Ku}$ and thus is refractory to nucleolytic processing. On the lagging end telomere, removal of the terminal RNA primer creates a G-overhang that will be bound by CST. Telomeres with G-overhangs can be extended by telomerase, while blunt-ended telomeres cannot. (B) In the absence of $\mathrm{Ku}$, blunt-ended telomeres are resected by Exol and other nucleases to create a G-overhang that is a suitable substrate for CST. Both ends are now symmetrical and accessible to telomerase. $(C)$ When both $\mathrm{Ku}$ and STN1 are deleted, all telomeres become unprotected due to inactivation of CST, leading to unregulated C-strand degradation and the activation of a DNA damage response.

\section{Ku: safeguarding blunt-ended telomeres for a better tomorrow}

Blunt-ended telomeres provoke an ATM-dependent DNA damage response in vertebrates that leads to chromosome end-joining reactions (Wu et al. 2010). If half of the chromosomes in Arabidopsis terminate in blunt ends or nearly blunt ends, how do such telomeres perform the critical function of preserving genome integrity? The answer comes from a protein complex that is both friend and foe to telomeres: $\mathrm{Ku}$. The $\mathrm{Ku}$ heterodimer (Ku70/Ku80) is a core component of the nonhomologous end-joining DNA repair pathway. $\mathrm{Ku}$ is a highly conserved ringed complex that encircles dsDNA, thereby loading onto ends created at double-strand breaks (DSBs) irrespective of sequence (Mari et al. 2006). Ku bound to a DNA end stabilizes the terminus by blocking nucleolytic degradation and additionally recruits factors necessary for the regulated processing and repair of the DSB (Riha et al. 2006).

Although $\mathrm{Ku}$ promotes DNA end-joining reactions at sites of DNA damage, it is an integral constituent of telomeres, where it prevents nucleolytic resection and end-to-end chromosome fusions (Lopez et al. 2011). In yeast, $\mathrm{Ku}$ controls C-strand resection alongside the Rap1/ Rif1/Rif2 complex (Bonetti et al. 2010b). Whereas Rap1 is responsible for inhibiting inappropriate nucleolytic digestion of telomeres during G1 and G2 phases of the cell cycle, Ku predominantly inhibits resection during G1. In human cells, conditional loss of $\mathrm{Ku}$ results in the rapid loss of telomeric DNA, presumably via a recombinationbased process termed telomere rapid deletion (TRD) that leads to rapid cell death (Wang et al. 2009). In contrast, Arabidopsis grows undeterred in the absence of $\mathrm{Ku}$ (Riha et al. 2002). Nevertheless, the telomeres do suffer: The rate of TRD is elevated (Zellinger et al. 2007), and the G-overhang signal is significantly increased (Riha and Shippen 2003), consistent with increased C-strand resection. Moreover, bulk telomeres are dramatically elongated in a telomerase-dependent fashion (Gallego et al. 2003; Riha and Shippen 2003). This latter finding was particularly puzzling because Ku-deficient telomeres are shorter in yeast, not longer (Boulton and Jackson 1996). Since telomerase enzyme activity levels are wild type in Arabidopsis ku mutants, $\mathrm{Ku}$ must somehow inhibit telomerase action at chromosome ends.

Given the critical role of $\mathrm{Ku}$ in binding DNA breaks and its important but enigmatic function at Arabidopsis telomeres, Kazda et al. (2012) asked how blunt-ended telomeres were affected by the loss of Ku. The ultralong telomeres in this genetic background would be difficult to analyze, and so the investigators examined the much shorter telomeres generated in plants doubly deficient for $\mathrm{Ku} 70$ and the telomerase catalytic subunit TERT (telomerase reverse transcriptase). Remarkably, all of the blunt-ended telomeres disappeared, likely due to unfettered C-strand resection on leading end telomeres. Arabidopsis can clearly cope with G-overhangs at both ends of its chromosomes, since ku mutants are healthy.

Whether $\mathrm{Ku}$ acts in concert with other telomerespecific factors to protect blunt-ended chromosomes is an open question. Nevertheless, these findings provide an explanation for the dramatic telomere elongation associated with the loss of $\mathrm{Ku}$. Blunt-ended telomeres are not a substrate for telomerase (Lingner and Cech 1996), and consequently their conversion to telomeres with G-overhangs would double the number of telomerase substrates (Fig. 2B). Over successive cell cycles, bulk telomere length would increase. Thus, blunt-ended telomeres effectively modulate telomere length in Arabidopsis by forcing telomerase to act, at the most, on only half of the telomeres each cell cycle.

\section{$\mathrm{Ku}$ and CST play musical chairs at the chromosome end}

Plants encode only a subset of the vertebrate shelterin components, and in Arabidopsis, genetic redundancy has hampered analysis of the putative orthologs that can be discerned (Karamysheva et al. 2004). The CST complex has recently emerged as a key regulator of telomere integrity in both vertebrates and plants (Miyake et al. 2009; Surovtseva et al. 2009; Price et al. 2010). CST binds ssDNA (Miyake et al. 2009), colocalizes with telomeres in vivo, and inhibits C-strand resection (Song et al. 2008; Surovtseva et al. 2009). Studies in yeast previously established that $\mathrm{Ku}$ and the CST complex perform genetically distinct 
roles at telomeres (Nugent et al. 1998; Maringele and Lydall 2002), setting the stage for Kazda et al. (2012) to ask whether Ku and CST protect opposite ends of Arabidopsis chromosomes. They found that loss of STN1, a core component of CST (Song et al. 2008), did not alter the percentage of blunt-ended telomeres. Although there was an increase in G-overhang signal, only $50 \%$ of the chromosomes harbored single-strand tails (Kazda et al. 2012), indicating that CST protects just a fraction of plant telomeres. Strikingly, stn1 ku 70 double mutants exhibited massive end-to-end chromosome fusions and arrested development, consistent with complete telomere failure (Fig. 2C). Finally, the investigators confirmed that Ku-depleted telomeres are resected primarily, but not exclusively, by Exol, the same enzyme implicated in C-strand resection in yeast (Bertuch and Lundblad 2004).

The division of labor between $\mathrm{Ku}$ and CST means that these two complexes are highly dynamic. Each time the cell replicates its DNA, the leading end telomere will give rise to both a leading telomere and a lagging telomere and vice versa (Fig. 1). Hence, half of the telomeres generated must acquire an end-binding complex distinct from their parent. How does changing of the telomere guard occur? Recent data from human cells indicate that newly replicated chromosome ends are rapidly bound by capping proteins. CST physically associates with DNA polymerase $\alpha /$ primase (Casteel et al. 2009), where it is proposed to promote telomeric DNA replication by priming telomeric C-strand synthesis (Gu et al. 2012; Nakaoka et al. 2012). Thus, CST would be in the vicinity of the chromosome terminus immediately following replication. Precisely how CST hands off the G-overhang to shelterin after telomeric DNA replication concludes and which of these complexes recruits telomerase is unknown.

As with G-overhang-binding proteins, the recruitment of Ku to newly formed blunt-ended telomeres is likely to be rapid and highly regulated. Chow et al. (2012) found a 1 -h lag between the conclusion of leading strand replication and G-overhang formation in human cells. During this interval, Ku could load onto blunt ends, providing a temporary cap on the terminus prior to C-strand resection (Fig. 1C). Supporting this proposal are data showing that leading telomeres in vertebrates are particularly susceptible to end-joining reactions when Ku-associated factors are depleted (Bailey et al. 2001). Finally, since biochemical evidence suggests that $\mathrm{Ku}$ must slide internally to allow for CST binding (Fig. 1C; Wu et al. 2009), the accumulation of Ku-bound blunt-ended telomeres in Arabidopsis may reflect an early exit from the telomere cap assembly line.

\section{Are blunt-ended telomeres a healthier choice for genome maintenance?}

Relative to organisms with G-overhangs on both chromosome ends, species with Ku-bound blunt-ended telomeres should display more subtle telomere length fluctuations, since access to both exonucleases and telomerase would be restricted on half of the chromosomes. Indeed, telomere tracts on individual chromosome ends are remark- ably homogenous throughout the Arabidopsis life span. Moreover, when telomerase is inactivated, telomeres shorten by a mere $250 \mathrm{nt}$ across each plant generation (Riha et al. 2001), implying that, overall, telomerase adds very few nucleotides when it engages chromosomes. Telomere length stability may be advantageous for sessile plants. It could extend the proliferation potential of stem cell niches as well as cells lacking telomerase, a nice trick in adapting to changing environmental conditions. The stability of blunt-ended telomeres and their potential to extend proliferation capacity may be less attractive to mammals facing the threat of metastatic cancer. The more dynamic nature of telomeres with G-overhangs offers a greater range of regulatory control. In conjunction with the inexorable march toward replicative senescence in cells lacking telomerase, a rapid response can be mounted to genome assaults that lead to incomplete DNA replication or loss of G-overhang protection, culminating in the elimination of cells with dysfunctional telomeres and the genome instability they incite.

\section{Acknowledgments}

We are grateful to Alison Bertuch for insightful comments on the manuscript. Research in the Shippen laboratory is supported by grants from NIH (R01-GM065383) and NSF (MCB-1052018).

\section{References}

Aichinger E, Kornet N, Friedrich T, Laux T. 2012. Plant stem cell niches. Annu Rev Plant Biol 63: 615-636.

Bailey SM, Cornforth MN, Kurimasa A, Chen DJ, Goodwin EH. 2001. Strand-specific postreplicative processing of mammalian telomeres. Science 293: 2462-2465.

Bertuch AA, Lundblad V. 2004. Exol contributes to telomere maintenance in both telomerase-proficient and telomerasedeficient Saccharomyces cerevisiae. Genetics 166: 1651-1659.

Bonetti D, Clerici M, Anbalagan S, Martina M, Lucchini G, Longhese MP. 2010a. Shelterin-like proteins and Yku inhibit nucleolytic processing of Saccharomyces cerevisiae telomeres. PLoS Genet 27: e1000966. doi: 10.1371/journal.pgen. 1000966.

Bonetti D, Clerici M, Manfrini N, Lucchini G, Longhese MP. 2010b. The MRX complex plays multiple functions in resection of Yku- and Rif2-protected DNA ends. PLOS ONE 5: e14142. doi: 10.1371/journal.pone.0014142.

Boulton SJ, Jackson SP. 1996. Identification of a Saccharomyces cerevisiae Ku80 homologue: Roles in DNA double strand break rejoining and in telomere maintenance. Nucleic Acids Res 24: 4639-4648.

Casteel DE, Zhuang S, Zeng Y, Perrino FW, Boss GR, Goulian M, Pilz RB. 2009. A DNA polymerase- $\alpha$ /primase cofactor with homology to replication protein A-32 regulates DNA replication in mammalian cells. J Biol Chem 284: 5807-5818.

Chow TT, Zhao Y, Mak SS, Shay JW, Wright WE. 2012. Early and late steps in telomere overhang processing in normal human cells: The position of the final RNA primer drives telomere shortening. Genes Dev 26: 1167-1178.

de Lange T. 2005. Shelterin: The protein complex that shapes and safeguards human telomeres. Genes Dev 19: 2100-2110.

Gallego ME, Jalut N, White CI. 2003. Telomerase dependence of telomere lengthening in Ku80 mutant Arabidopsis. Plant Cell 15: 782-789. 
Gu P, Min JN, Wang Y, Huang C, Peng T, Chai W, Chang S. 2012. CTC1 deletion results in defective telomere replication, leading to catastrophic telomere loss and stem cell exhaustion. EMBO J 31: 2309-2321.

Henderson ER, Blackburn EH. 1989. An overhanging 3' terminus is a conserved feature of telomeres. Mol Cell Biol 9: 345348.

Karamysheva ZN, Surovtseva YV, Vespa L, Shakirov EV, Shippen DE. 2004. A C-terminal Myb extension domain defines a novel family of double-strand telomeric DNA-binding proteins in Arabidopsis. I Biol Chem 279: 47799-47807.

Kazda A, Zellinger B, Rössler M, Derboven E, Kusenda B, Riha K. 2012. Chromosome end protection by blunt-ended telomeres. Genes Dev (this issue). doi: 10.1101/gad.194944.112.

Lingner J, Cech TR. 1996. Purification of telomerase from Euplotes aediculatus: Requirement of a primer 3' overhang. Proc Natl Acad Sci 93: 10712-10717.

Lopez CR, Ribes-Zamora A, Indiviglio SM, Williams CL, Haricharan S, Bertuch AA. 2011. Ku must load directly onto the chromosome end in order to mediate its telomeric functions. PLOS Genet 7: e1002233. doi: 10.1371/journal.pgen. 1002233.

Makarov VL, Hirose Y, Langmore JP. 1997. Long G tails at both ends of human chromosomes suggest a $\mathrm{C}$ strand degradation mechanism for telomere shortening. Cell 88: 657-666.

Mari PO, Florea BI, Persengiev SP, Verkaik NS, Bruggenwirth HT, Modesti M, Giglia-Mari G, Bezstarosti K, Demmers JA, Luider TM, et al. 2006. Dynamic assembly of end-joining complexes requires interaction between $\mathrm{Ku} 70 / 80$ and XRCC4. Proc Natl Acad Sci 103: 18597-18602.

Maringele L, Lydall D. 2002. EXO1-dependent single-stranded DNA at telomeres activates subsets of DNA damage and spindle checkpoint pathways in budding yeast yku70s mutants. Genes Dev 16: 1919-1933.

Miyake Y, Nakamura M, Nabetani A, Shimamura S, Tamura M, Yonehara S, Saito M, Ishikawa F. 2009. RPA-like mammalian Ctc1-Stn1-Ten1 complex binds to single-stranded DNA and protects telomeres independently of the Potl pathway. Mol Cell 36: 193-206.

Nakaoka H, Nishiyama A, Saito M, Ishikawa F. 2012. Xenopus laevis Ctc1-Stn1-Ten1 (xCST) protein complex is involved in priming DNA synthesis on single-stranded DNA template in Xenopus egg extract. J Biol Chem 287: 619-627.

Nugent CI, Bosco G, Ross LO, Evans SK, Salinger AP, Moore JK, Haber JE, Lundblad V. 1998. Telomere maintenance is dependent on activities required for end repair of double-strand breaks. Curr Biol 8: 657-660.

Oganesian L, Karlseder J. 2011. Mammalian 5' C-rich telomeric overhangs are a mark of recombination-dependent telomere maintenance. Mol Cell 42: 224-236.

Olovnikov AM. 1973. A theory of marginotomy. The incomplete copying of template margin in enzymic synthesis of polynucleotides and biological significance of the phenomenon. J Theor Biol 41: 181-190.

Price CM, Boltz KA, Chaiken MF, Stewart JA, Beilstein MA, Shippen DE. 2010. Evolution of CST function in telomere maintenance. Cell Cycle 9: 3157-3165.

Raices M, Verdun RE, Compton SA, Haggblom CI, Griffith JD, Dillin A, Karlseder J. 2008. C. elegans telomeres contain G-strand and C-strand overhangs that are bound by distinct proteins. Cell 132: 745-757.

Raffa GD, Raimondo D, Sorino C, Cugusi S, Cenci G, Cacchione S, Gatti M, Ciapponi L. 2010. Verrocchio, a Drosophila OB fold-containing protein, is a component of the terminin telomere-capping complex. Genes Dev 24: 1596-1601.
Riha K, Shippen DE. 2003. Ku is required for telomeric C-rich strand maintenance but not for end-to-end chromosome fusions in Arabidopsis. Proc Natl Acad Sci 100: 611-615.

Riha K, McKnight TD, Fajkus J, Vyskot B, Shippen DE. 2000. Analysis of the G-overhang structures on plant telomeres: Evidence for two distinct telomere architectures. Plant $/ 23$ : 633-641.

Riha K, McKnight TD, Griffing LR, Shippen DE. 2001. Living with genome instability: Plant responses to telomere dysfunction. Science 291: 1797-1800.

Riha K, Watson JM, Parkey J, Shippen DE. 2002. Telomere length deregulation and enhanced sensitivity to genotoxic stress in Arabidopsis mutants deficient in Ku70. EMBO I 21: 2819-2826.

Riha K, Heacock ML, Shippen DE. 2006. The role of the nonhomologous end-joining DNA double-strand break repair pathway in telomere biology. Annu Rev Genet 40: 237-277.

Sfeir AJ, Chai W, Shay JW, Wright WE. 2005. Telomere-end processing the terminal nucleotides of human chromosomes. Mol Cell 18: 131-138.

Song X, Leehy K, Warrington RT, Lamb JC, Surovtseva YV, Shippen DE. 2008. STN1 protects chromosome ends in Arabidopsis thaliana. Proc Natl Acad Sci 105: 19815-19820.

Surovtseva YV, Churikov D, Boltz KA, Song X, Lamb JC, Warrington $R$, Leehy $K$, Heacock $M$, Price CM, Shippen DE. 2009. Conserved telomere maintenance component 1 interacts with STN1 and maintains chromosome ends in higher eukaryotes. Mol Cell 36: 207-218.

van Overbeek M, de Lange T. 2006. Apollo, an Artemis-related nuclease, interacts with TRF2 and protects human telomeres in S phase. Curr Biol 16: 1295-1302.

Wang Y, Ghosh G, Hendrickson EA. 2009. Ku86 represses lethal telomere deletion events in human somatic cells. Proc Natl Acad Sci 106: 12430-12435.

Watson JD. 1972. Origin of concatemeric T7 DNA. Nat New Biol 239: 197-201.

Wellinger RJ, Wolf AJ, Zakian VA. 1993. Saccharomyces telomeres acquire single-strand TG1-3 tails late in S phase. Cell 72: $51-60$.

Wu TJ, Chiang YH, Lin YC, Tsai CR, Yu TY, Sung MT, Lee YH, Lin JJ. 2009. Sequential loading of Saccharomyces cerevisiae $\mathrm{Ku}$ and Cdc13p to telomeres. J Biol Chem 284: 12801-12808.

Wu P, van Overbeek M, Rooney S, de Lange T. 2010. Apollo contributes to $\mathrm{G}$ overhang maintenance and protects leadingend telomeres. Mol Cell 39: 606-617.

Zellinger B, Akimcheva S, Puizina J, Schirato M, Riha K. 2007. $\mathrm{Ku}$ suppresses formation of telomeric circles and alternative telomere lengthening in Arabidopsis. Mol Cell 27: 163-169. 


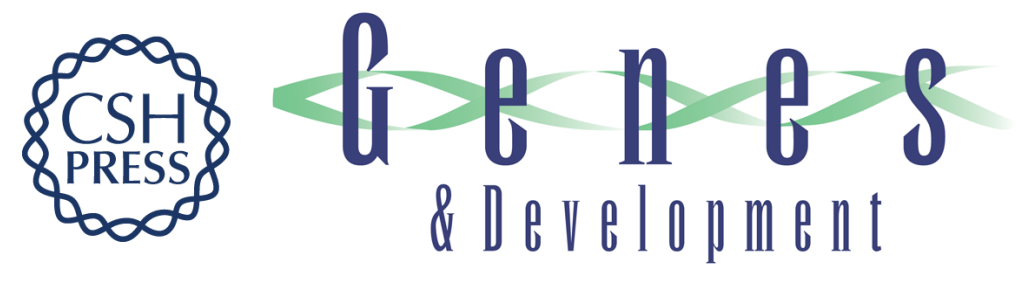

\section{Blunt-ended telomeres: an alternative ending to the replication and end protection stories}

Andrew D.L. Nelson and Dorothy E. Shippen

Genes Dev. 2012, 26:

Access the most recent version at doi:10.1101/gad.199059.112
Related Content Chromosome end protection by blunt-ended telomeres
Anita Kazda, Barbara Zellinger, Max Rössler, et al.
Genes Dev. August , 2012 26: 1703-1713
References This article cites 41 articles, 18 of which can be accessed free at:
http://genesdev.cshlp.org/content/26/15/1648.full.html\#ref-list-1
Articles cited in:
http://genesdev.cshlp.org/content/26/15/1648.full.html\#related-urls
License
Email Alerting
Service $\begin{aligned} & \text { Receive free email alerts when new articles cite this article - sign up in the box at the top } \\ & \text { right corner of the article or click here. }\end{aligned}$

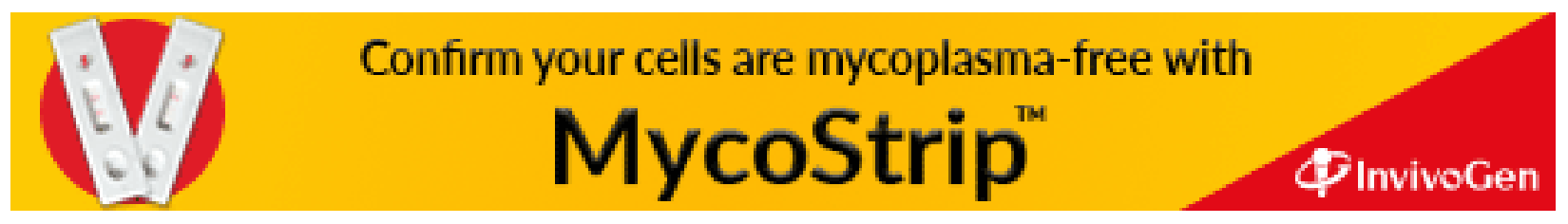

